\title{
Prediction Method of Tunnel Deformation Using Time-dependent Ground Deterioration Model
}

\section{Keisuke SHIMAMOTO \\ Researcher,}

\section{Kazuhide YASHIRO}

Assistant Senior Researcher,

Tunnel Laboratory, Structure Technology Division
Yoshiyuki KOJIMA, Dr. Eng. Laboratory Head,

\author{
Toshihiro ASAKURA, Dr. Eng. \\ Professor, \\ Kyoto University Graduate School of Engineering
}

\begin{abstract}
Some mountain tunnels suffer from deformation and cracks caused by earth pressure, and such damage can progress with the passage of time for some tunnels. Due the unknown variables involved in the time-dependent deformation and destruction behavior of such tunnels, no maintenance management method has yet been established. In this study, we focused on tunnel deformation caused by earth pressure, and attempted to apply numerical analysis to the situation. As the result of the study, we achieved simulation of the behavior of tunnel deformation as time progressed and demonstrated the applicability of determination for appropriate timing and countermeasure types.
\end{abstract}

Keywords: tunnel, earth pressure, deformation, numerical analysis, prediction

\section{Introduction}

Mountain tunnels are subject to deformation and cracking caused by ground pressure after they are constructed. As such structures normally cannot be replaced with newly constructed ones, it is necessary to appropriately control and maintain tunnels that become deformed. As a number of factors affect time-dependent tunnel deformation behavior, however, techniques have not yet been established to control and maintain tunnels damaged by ground pressure.

Against such a background, the authors are now studying techniques for numerical analysis/simulation and methods to predict deformation in order to propose a long-term control and maintenance method for tunnels deformed by ground pressure [1].

By following previously published study results [1], this paper introduces the outcome of discussions on the relationships between the configuration of strength reduction curves and the progress of deformation, the validity of the analytical technique adopted in this study and its application to the real world.

In this study, the authors first introduced configurations of strength reduction curves, analyzed tunnel deformation on a trial basis and proved that the proposed strength reduction curves correctly expressed the progress of typical tunnel deformation. To ascertain the applicability of the ground deterioration model for practical purposes, the authors implemented trial analysis applying the data obtained from the above geological boring survey along with countermeasures and the timing of their implementation as parameters. Discussions were then conducted on the applicability of analysis using a ground deterioration model in studies on countermeasures for deformed tunnels.

\section{Analysis technique}

The authors used a ground deterioration model for the analysis in this study. The model changes strength constants for different ground elements in order to express reduced ground strength over time and reproduce tunnel convergence behavior.

Figure 1 shows the concept of in-ground strength reduction. Assuming that ground consists of a material that follows the Mohr-Coulomb yield criterion, the authors set a function to express the tendency of ground to lose strength over time (the strength reduction curve in Fig. 1) based on the results of the boring survey from the inside of a tunnel and the measurement of tunnel deformation. In the analysis, the authors reduced the ground strength to follow the strength reduction curve. Although the ground strength decreased evenly in this analysis over the entire modeling zone as a result, the ground did not break in areas far from the tunnel where stress concentration was smaller, even though its strength was substantially reduced. The evenness of the reduction in strength over the entire zone did not therefore affect the results of the analysis.

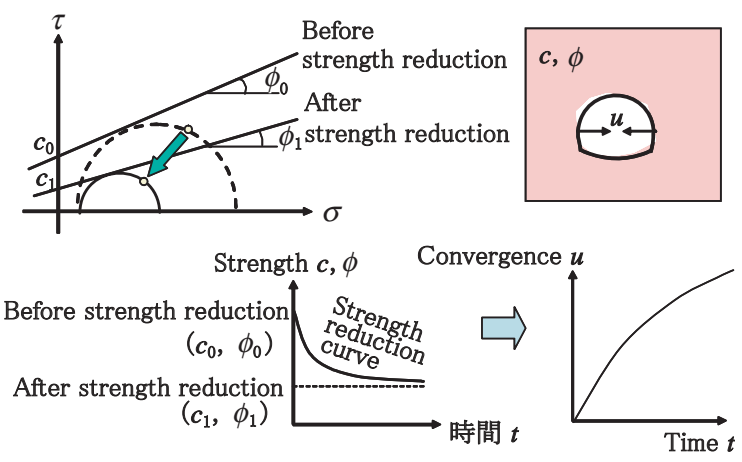

Fig. 1 Expression of in-ground strength reduction 


\section{Configurations of strength reduction curves and deformation progress}

\subsection{Assumption of strength reduction curves}

In line with the results of case studies performed by the authors in the past, Fig. 2 shows the progress of convergence (i.e., the shrinkage of a tunnel's dimensions in the horizontal direction) at typical cross sections of the Tagokura Tunnel [2] and Tunnel A on the Tadami line, which had been deformed in the past by ground pressure. The convergence speed increases over time with the Tagokura Tunnel, while it remains approximately constant for a long period of time with Tunnel A.

Bearing in mind the above concept of the progress of tunnel convergence, the authors assumed the following three types of strength reduction curve:

Straight line type:

$$
c=c_{0}-A t
$$

Exponential curve type:

$$
c=c_{0} \times \exp (-A t)
$$

Logarithmic curve time:

$$
c=c_{0}-A \times \ln (t+1)
$$

where

$A=$ Coefficient

$t=$ Years after the tunnel was put into use

$c_{0}=$ Initial ground strength (cohesion)

According to the above-mentioned boring survey, the strength reduction in the ground is more conspicuous in

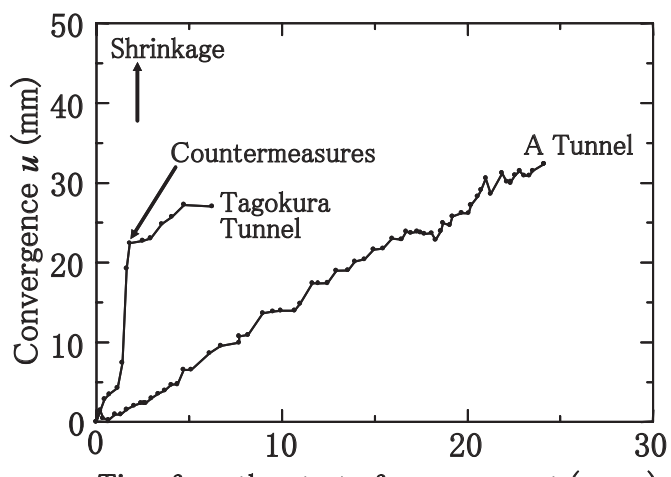

Time from the start of measurement (years)

Fig. 2 Progress of convergence

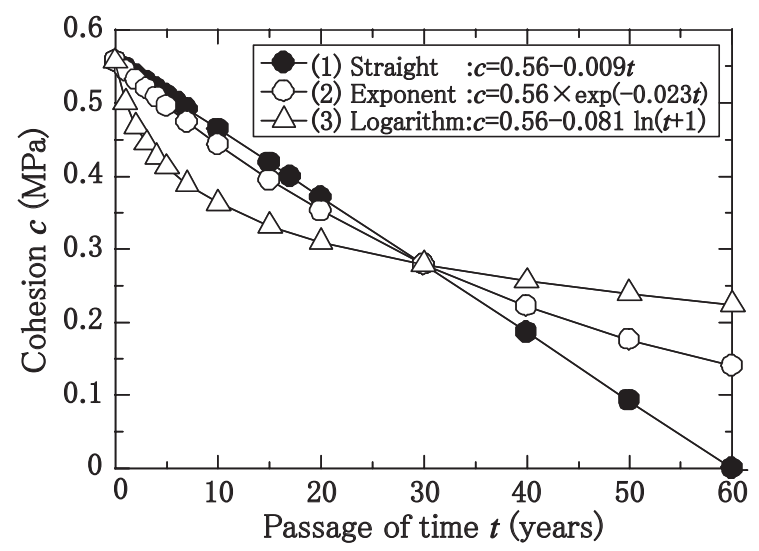

Fig. 3 Assumed strength reduction curves cohesion than in the internal friction angle; the authors assume that the strength reduction can be expressed by the decrease in cohesion. It is possible to model almost all deformation patterns with these three lines/curves other than exceptionally abnormal deformation.

Figure 3 shows the strength reduction curve when $c_{0}$ is set at $0.56 \mathrm{MPa}$ (with the unconfined strength assumed as $\mathrm{qu}=2.0 \mathrm{MPa}$ according to formulae in published literature $[3,4])$ and $\mathrm{A}$ is a value to make cohesion $c_{0} / 2$ at a point 30 years after the start of deterioration. The authors used these strength reduction curves for analysis on a trial basis.

\subsection{Other conditions for analysis}

Other than the ground strength reduction curves, the ground data listed in Table 1 were used as the conditions for analysis. The authors modeled the ground as a material that satisfies the Mohr-Coulomb yield criterion, and set the initial unconfined strength at $2 \mathrm{MPa}$ (by assuming soft rock from the Neogene period) and the coefficient of lateral pressure at 0.43 (by assuming a state of homogeneous and isotropic plane strain at a Poisson's ratio of 0.3 ). After determining the values of cohesion $c$ and elastic modulus $E$ of the ground by referring to published literature $[3,4]$ that proposes a static correlation formula for the unconfined strength and other material property values, the authors expressed the deterioration of the ground by reducing the value of cohesion $c$, one of the shearing strength constants of the ground.

Table 2 lists data on the lining used for analysis. The structure adopted for the investigation was an ordinary narrow-gauge single-track tunnel. The authors modeled the lining as an easy-to-handle material that follows the Mohr-Coulomb yield criterion in the same way as for the ground, with the rigidity set at 0 to express the occurrence of cracking when the generated tensile stress has exceeded the tensile strength of concrete.

Figure 4 shows the analytical model, which represents a half cross-sectional area of the tunnel on the right-hand side to take advantage of the symmetry of tunnel configuration. Regarding the areas $50 \mathrm{~m}$ or more away in the vertical and lateral directions from the tunnel in this model, the boundary nodes were imposed with the selfweight of the ground in the vertical direction and with the vertical load multiplied by the coefficient of lateral

\begin{tabular}{|c|c|c|}
\hline Parameter & Input value & Remarks \\
\hline Overburden $h(\mathrm{~m})$ & 100 & \multirow{3}{*}{$\begin{array}{l}\text { Define these values } \\
\text { to set the ratio of } \\
\text { rock mass strength } \\
\text { to overburden } \\
\text { pressure }(q / \gamma h)=1\end{array}$} \\
\hline Unit weight $\gamma\left(\mathrm{kN} / \mathrm{m}^{3}\right)$ & 20 & \\
\hline $\begin{array}{l}\text { Uniaxial compressive } \\
\text { strength } q_{u}(\mathrm{MPa})\end{array}$ & 2 & \\
\hline Poisson's ratio $v$ & 0.3 & Ordinary value \\
\hline Stiffness coefficient $E(\mathrm{MPa})$ & 240 & \multirow{2}{*}{ Set by reference ${ }^{8) \sim 10}$} \\
\hline Cohesion $c(\mathrm{MPa})$ & 0.56 & \\
\hline Internal friction angle $\phi\left(^{\circ}\right)$ & 30 & Ordinary value \\
\hline $\begin{array}{l}\text { Coefficient of lateral } \\
\text { pressure } K\end{array}$ & 0.43 & $K=v /(1-v)$ \\
\hline
\end{tabular}
pressure in the horizontal direction.

Table 1 Data used for analysis (ground) 
Table 2 Data used for analysis (lining)

\begin{tabular}{|c|c|c|}
\hline Parameter & Input value & Remarks \\
\hline Thickness of lining $t(\mathrm{~mm})$ & 450 & Ordinary value \\
\hline Stiffness coefficient $E(\mathrm{MPa})$ & $2.1 \times 10^{4}$ & \multirow{5}{*}{$\begin{array}{l}\text { Assuming } \\
\sigma_{c k}=18 \mathrm{~N} / \mathrm{mm}^{2}\end{array}$} \\
\hline Poisson's ratio $v$ & 0.2 & \\
\hline Cohesion $c(\mathrm{MPa})$ & 5.2 & \\
\hline Tensile strength $\sigma_{t}(\mathrm{MPa})$ & 1.6 & \\
\hline Internal friction angle $\phi\left(^{\circ}\right)$ & 30 & \\
\hline Back void & Exist & $\begin{array}{l}\text { Express by none } \\
\text { value element }\end{array}$ \\
\hline Invert & None & \\
\hline
\end{tabular}

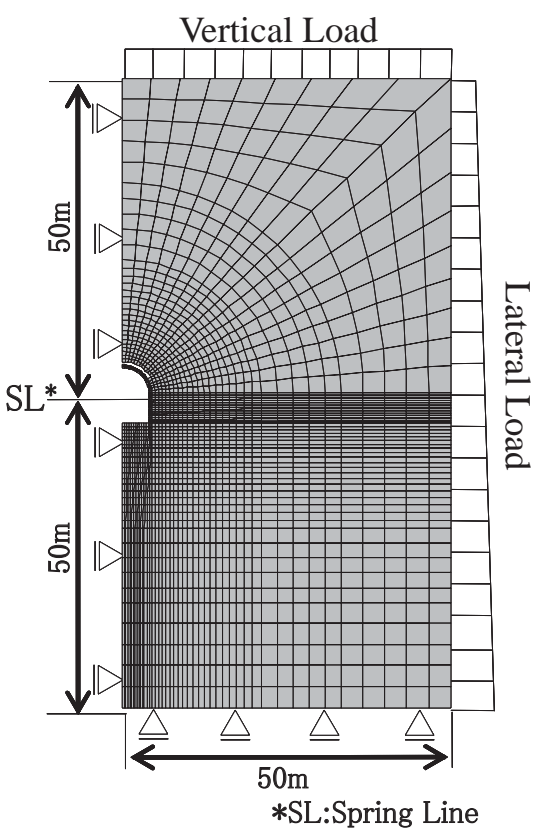

Fig. 4 Model used for analysis

\subsection{Results of analysis}

Figure 5 shows the progress of convergence obtained through the analysis. The convergence speed is small when the time (years of service) $t$ is small. However, it increases over time with the types of (1) straight line and (2) exponential curve, and decreases slightly over time or remains approximately constant with the type of (3) logarithmic curve compared to the cases of (1) and (2).

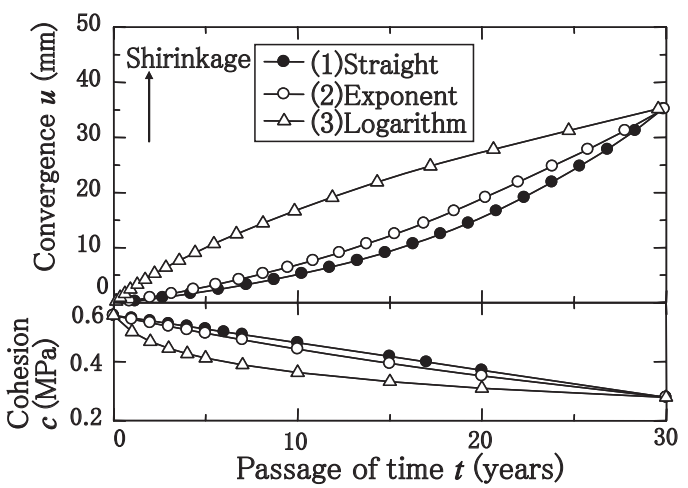

Fig. 5 Progress of convergence
From the above, it is conceivable that the strength reduction curve can be assumed with approximation formulae (1) or (2) for deformation where the convergence speed increases over time (as in the case of the Tagokura Tunnel in Fig. 2) and with approximation formula (3) for deformation where the convergence speed is comparatively constant (as in the case of Tunnel A).

\section{Simulation analysis}

The discussions in Section 3 prove that different configurations of strength reduction curve represent different deformation patterns with a convergence speed that increases or remains almost constant over time.

This section introduces the case of the Tagokura Tunnel (a structure that was deformed by ground pressure in the past, for which a boring survey was implemented) for detailed analysis to reproduce the total deformation and confirm the validity of the analysis technique adopted in this study.

\subsection{Summary}

The Tagokura Tunnel [2] is located in ground composed of green tuff and rhyolite from the Miocene epoch of the Neogene period. Shortly after it was put into service, it suffered deformation including horizontal convergence (approximately $15 \mathrm{~mm} /$ year on average), cracking and compression fracture at a point $94.590 \mathrm{~km}$ from AizuWakamatsu, the starting point of the Tadami line. Table 3, Fig. 6 and Fig. 7 show the dimensions of the tunnel, the progress of convergence and a schematic drawing of the structure's deformation (in cross-sectional profile), respectively.

The cause of the deformation is thought to have been the yield-causing pressure of the ground. Such a judgment is made in consideration of factors such as the horizontal convergence over time, compression fracture at the crown, tensile cracking on the sidewalls and the ratio of rock mass strength to overburden pressure, which is as small as approximately 1.3. The deformation has now settled due to the effects of countermeasures such as backfill grouting and the installation of rock bolts.

To obtain the material property values required for numerical analysis prior to the analysis, the authors performed a geological survey by boring from inside the tunnel at the point where cracking and other types of failure had occurred (refer to Fig. 8 for the results of the geologi-

Table 3 Dimensions of the Tagokura Tunnel

\begin{tabular}{|l|l|}
\hline Length & $3,712 \mathrm{~m}$ \\
\hline Completion & 1971 \\
\hline $\begin{array}{l}\text { Method of } \\
\text { excavation }\end{array}$ & Conventional method (Full face excavation) \\
\hline $\begin{array}{l}\text { Geological } \\
\text { condition }\end{array}$ & Green tuff and rhyolite from the Miocene \\
\hline Structure & $\begin{array}{l}\text { Thickness of lining } 230 \sim 450 \mathrm{~mm}, \text { Invert } \\
\text { exists in some zones }\end{array}$ \\
\hline Repair history & Backfill, Rock bolts \\
\hline
\end{tabular}




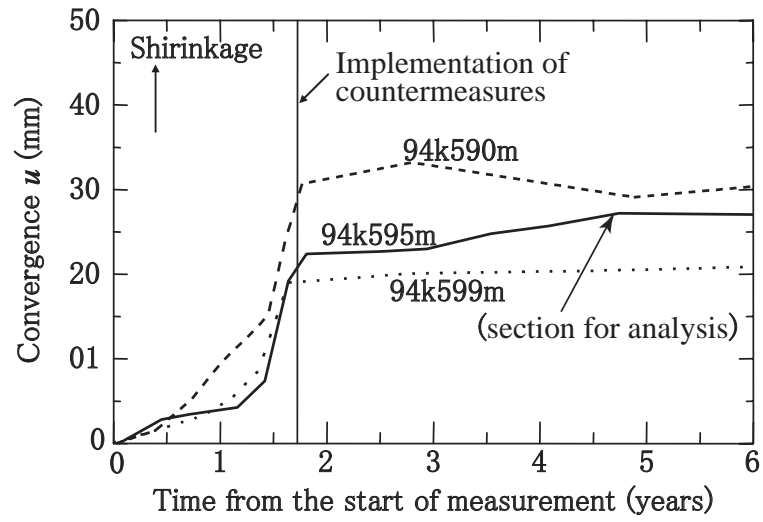

Fig. 6 Progress of convergence in the Tagokura Tunnel

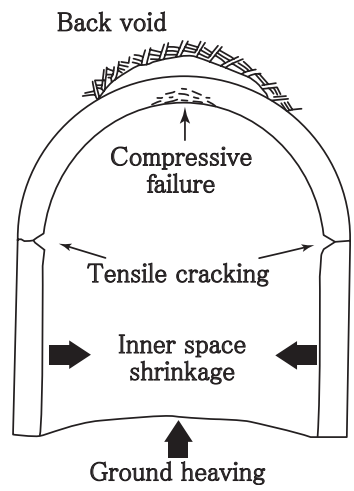

Fig. 7 Schematic drawing of deformation in the Tagokura Tunnel (in cross-sectional profile)

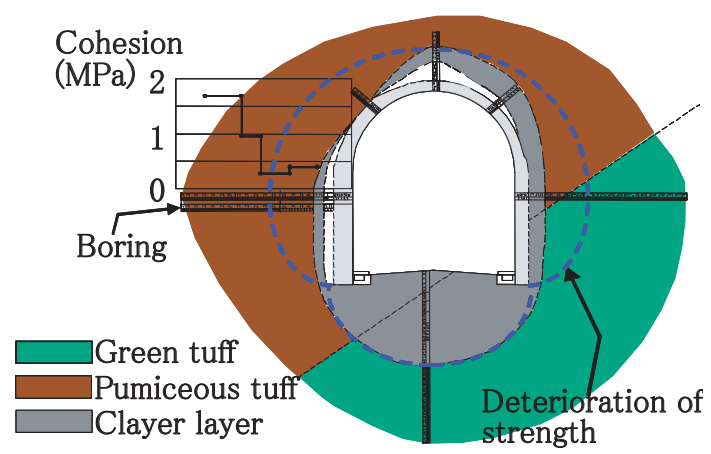

Fig. 8 Geological survey results

cal survey). The ground is composed of green and pumiceous tuff that is prone to weathering, with a $50 \mathrm{~cm}$-thick clayey layer between the crown and the sidewall. Around the tunnel, a 1 to $2 \mathrm{~m}$-thick zone was assumed to exist where the strength had decreased according to the results of laboratory investigation and in-situ tests performed on the left sidewall.

\subsection{Conditions for analysis}

Table 4 shows the data of the ground used for this analysis, which were principally set based on the results of the geological survey. More specifically, data from nondeteriorated ground were used for the initial strength, and those of deteriorated ground were used for the residual strength. As the internal friction angle $\varphi$ and the
Table 4 Data used for analysis (ground)

\begin{tabular}{|l|l|l|}
\hline Parameter & Input value & Remarks \\
\hline Unit Weight $\gamma\left(\mathrm{kN} / \mathrm{m}^{3}\right)$ & 20 & Laboratory test \\
\hline $\begin{array}{l}\text { Stiffness coefficient } \\
E(\mathrm{MPa})\end{array}$ & 1,700 & $\begin{array}{l}\text { Borehole lateral load test } \\
\text { (Non-deterioration) }\end{array}$ \\
\hline Poisson's ratio $v$ & 0.33 & $\begin{array}{l}\text { Laboratory test } \\
\text { (Non-deterioration) }\end{array}$ \\
\hline Cohesion $c(\mathrm{MPa})$ & Initial 1.7 & $\begin{array}{l}\text { Laboratory test } \\
\text { (Non-deterioration) } \\
\text { Laboratory test } \\
\text { (Deterioration) }\end{array}$ \\
\hline $\begin{array}{l}\text { Internal friction angle } \\
\phi\left(^{\circ}\right)\end{array}$ & 10,20 & Ordinary value \\
\hline $\begin{array}{l}\text { Coefficient of lateral } \\
\text { pressure } K\end{array}$ & $0.8,1.0$ & Ordinary value \\
\hline
\end{tabular}

Table 5 Data used for analysis (lining)

\begin{tabular}{|c|c|c|}
\hline Parameter & Input value & Remarks \\
\hline Thickness of lining $t(\mathrm{~mm})$ & 300 & Ordinary value \\
\hline Stiffness coefficient $E$ (MPa) & $2.1 \times 10^{4}$ & \multirow{5}{*}{$\begin{array}{l}\text { Assuming } \\
\sigma_{c k}=18 \mathrm{~N} / \mathrm{mm}^{2}\end{array}$} \\
\hline Poisson's ratio $v$ & 0.2 & \\
\hline Cohesion $c(\mathrm{MPa})$ & 5.2 & \\
\hline Tensile strength $\sigma_{t}(\mathrm{MPa})$ & 1.6 & \\
\hline Internal friction angle $\phi\left(^{\circ}\right)$ & 30 & \\
\hline Back void & Exist & $\begin{array}{l}\text { Express by none } \\
\text { value element }\end{array}$ \\
\hline Invert & None & \\
\hline
\end{tabular}

Table 6 Data used for analysis (countermeasures)

\begin{tabular}{|l|l|l|l|}
\hline Parameter & \multicolumn{2}{|c|}{ Input value } & \multicolumn{1}{c|}{ Remarks } \\
\hline Backfill & & - & $\begin{array}{l}\text { Add ground elements to the } \\
\text { back void }\end{array}$ \\
\hline Rock bolts & $\begin{array}{l}\text { Stiffness } \\
\text { coefficient } \\
E(\mathrm{MPa})\end{array}$ & $2.1 \times 10^{5}$ & $\begin{array}{l}\phi=25 \mathrm{~mm}, L=4 \mathrm{~m} \text {, c.t.c }=1.5 \mathrm{~m} \\
10 \text { bolts } / \mathrm{section} \\
\text { Prestress } 70 \mathrm{kN} \text { per bolt }\end{array}$ \\
\hline
\end{tabular}

coefficient of lateral pressure $K$ (for which measurement data were unavailable), the values normally used were assumed initially as parameters for the analysis, and then actual data was determined by comparing the results of analysis with those of the geological survey. A detailed explanation of the data preparation process is not included in this paper due to space limitations.

Table 5 shows the lining data used for the analysis. The lining was modeled in the same way as the tunnel (explained in Section 3).

The countermeasures adopted were backfill grouting and rock bolts. For the purpose of analysis, the backfill grouting served to add ground elements to the backside void, with the rock bolts modeled for evaluation using the structural elements incorporated in the FLAC analytical software. The time taken to implement the countermeasures in the analysis was set at the actual time of application.

Table 6 lists data on the countermeasures used for the analysis, and Fig. 9 shows the model adopted. 


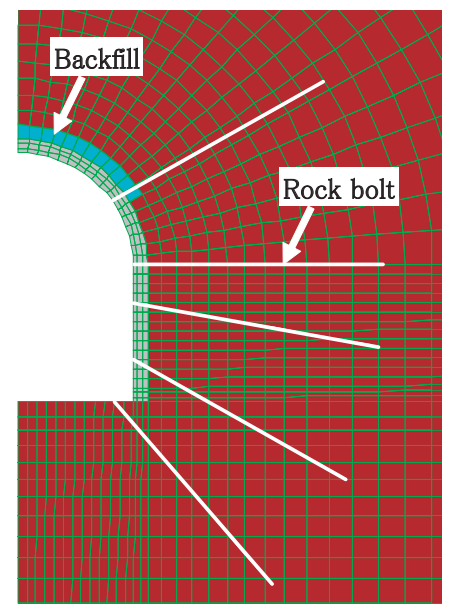

Fig. 9 Model for analysis

\subsection{Deformation-reproducing analysis}

Using the material property data referred to above, the authors implemented analysis to reproduce the measurement data. As the Tagokura Tunnel presents deformation of the (2) exponential type with an increased convergence speed over time (Fig. 7), the authors assumed that the ground strength (cohesion $c$ ) decreased according to the formula $c=c_{0} \times \exp (-A t)$ based on the trial analysis outlined in Section 3. By assuming that coefficient A was 0.08 (1/year) with the internal friction angle $\varphi$ kept constant, it was possible to appropriately express the measurement values of convergence during the period from the start of service to the time when the countermeasures were applied.

Figure 10 and Table 7 show the progress of convergence and the failure zone of the lining (where cracking or compression fracture occurred) shown in white, respectively. Regarding the progress of deformation (cracking), the authors judged that the phenomenon occurred when the stress at the tensile edge of the lining reached the tensile strength of concrete, and that compression fracture occurred when the stress at the compressive edge of the lining reached $3,500 \mu$, or the critical compression strain of concrete. Figure 10 and Table 7 show that deformation progressed through the following steps:

(1) Cracking at the backside of the crown

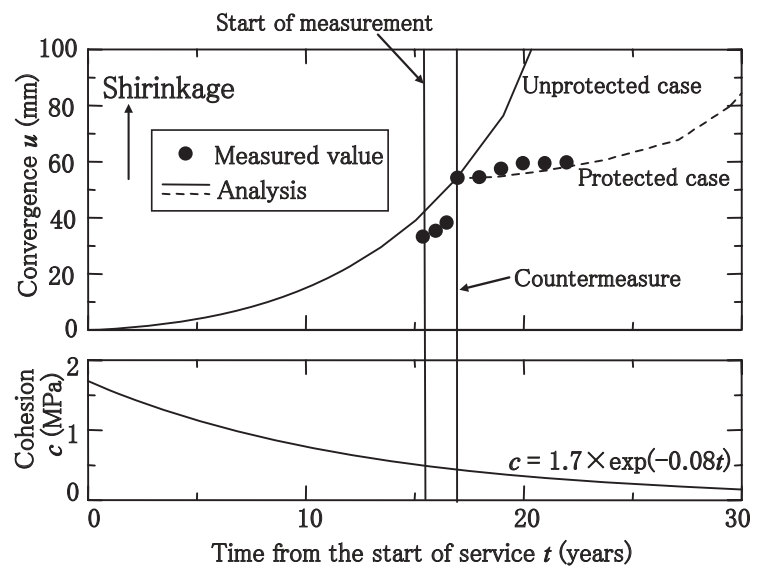

Fig. 10 Results of deformation-reproducing analysis
Table 7 Progress of lining fracture

\begin{tabular}{|l|l|}
\hline $\begin{array}{l}\text { (1) Cracking at the } \\
\text { backside of the crown } \\
\text { (6 years after the start of } \\
\text { service) }\end{array}$ & $\begin{array}{l}\text { (2) Cracking inside the } \\
\text { arch shoulder } \\
\text { (7 years after the start } \\
\text { of service) }\end{array}$ \\
\hline $\begin{array}{l}\text { Crack } \\
\text { (Reach the tensile } \\
\text { strength) }\end{array}$ & \\
\hline $\begin{array}{l}\text { (3) Cracking inside the } \\
\text { sidewall } \\
\text { (11 years after the start } \\
\text { of service) }\end{array}$ & $\begin{array}{l}\text { (4) Compression fracture } \\
\text { inside the crown } \\
\text { (17 years after the start } \\
\text { of service) }\end{array}$ \\
\hline & \\
\hline
\end{tabular}

(2) Cracking inside the arch shoulder

(3) Cracking inside the sidewall

(4) Compression fracture inside the crown

For simplicity of description in this report, let us define a case where countermeasures have been applied as a protected case and one where such measures have not been applied as an unprotected case.

\subsection{Effects of countermeasures}

Figure 10 shows the convergence speeds in protected and unprotected cases by different types of countermeasures, with solid lines representing protected cases and dotted lines unprotected cases. Figure 10 proves that deformation quickly increases in unprotected cases, while it is suppressed in protected cases. Figure 10 therefore appropriately reproduces the actual situation of deformation occurrence.

Table 8 shows the failure zone in white where the elastic modulus decreased due to fracture 15 years after the implementation of countermeasures. Table 8 shows that backfill grouting and other countermeasures suppress not only the deformation of the tunnel structure but also the expansion of the loosened zone in the surrounding ground. It has been confirmed that this analytical technique clarifies the effectiveness of backfill grouting in suppressing the deterioration (i.e., expansion of the loosened zone) of the ground, which was not possible with the conventional analytical method that observed only the behavior of the tunnel structure. 
Table 8 Changes in the failure zone in protected and unprotected cases

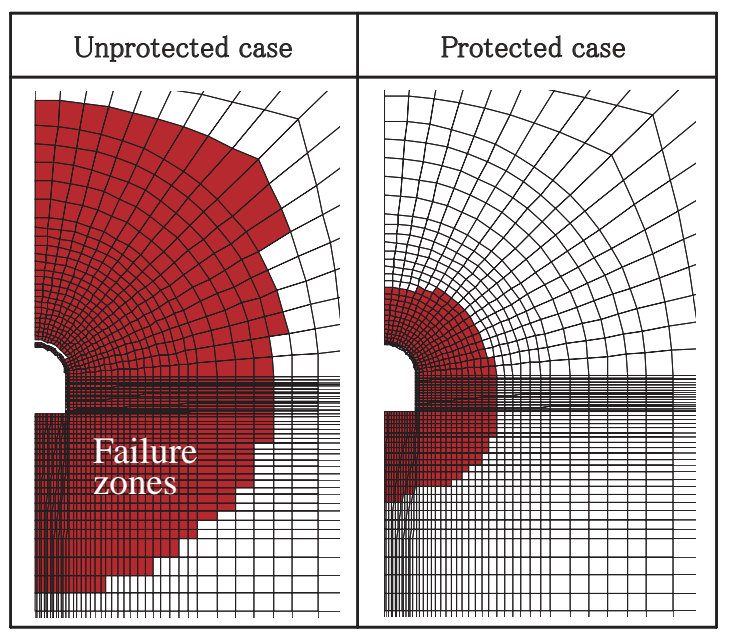

\subsection{Conclusion of analysis}

In the above investigation, the authors implemented simulation analysis on the Tagokura Tunnel while assuming ground strength reduction curves, and found that it was possible to reproduce tunnel deformation by using appropriately set input conditions.

Below, the authors discuss the effects and timing of implementing countermeasures based on the technique adopted in this study.

\section{Real-world application}

\subsection{Summary}

In this section, the authors discuss the feasibility of applying the technique studied above to the discussion of categories for countermeasures and the timing of their implementation.

\subsection{Conditions for analysis}

The authors adopted the model of the Tagokura Tunnel for analysis using data from the ground and the lining referred to in section 4.1 .

Countermeasures normally used for practical purposes - such as backfill grouting, rock bolts and struts were used as parameters (refer to Table 9 for the combination of countermeasures and Table 10 for the modeling thereof).

The authors then adopted three different times for the implementation of countermeasures: the actual time (17 years after the start of service) as a basis, two years before and two years after (see Table 11 for the different times of countermeasure application). Consequently, the authors adopted thirteen cases for analysis, including an unprotected case.
Table 9 Combination of countermeasures

\begin{tabular}{|c|c|c|c|}
\hline $\begin{array}{c}\text { Combina } \\
\text { tion }\end{array}$ & Backfill & $\begin{array}{c}\text { Rock } \\
\text { bolts }\end{array}$ & Struts \\
\hline 1 & $\bigcirc$ & & \\
\hline 2 & & 0 & \\
\hline 3 & $\bigcirc$ & $\bigcirc$ & \\
\hline 4 & $\bigcirc$ & 0 & 0 \\
\hline
\end{tabular}

Table 10 Modeling of countermeasures

\begin{tabular}{|l|l|l|l|}
\hline Parameter & \multicolumn{2}{|c|}{ Input value } & \multicolumn{1}{c|}{ Remarks } \\
\hline Backfill & & - & $\begin{array}{l}\text { Add ground elements to } \\
\text { the back void }\end{array}$ \\
\hline Rock bolts & $\begin{array}{l}\text { Stiffness } \\
\text { coefficient } \\
E(\mathrm{MPa})\end{array}$ & $2.1 \times 10^{5}$ & $\begin{array}{l}\phi=25 \mathrm{~mm}, L=4 \mathrm{~m} \\
10 \text { bolts/section, } \\
\text { c.t.c=1.5m } \\
\text { Prestress } 70 \mathrm{kN} \text { per bolt }\end{array}$ \\
\hline Struts & $\begin{array}{l}\text { Stiffness } \\
\text { coefficient } \\
E(\mathrm{MPa})\end{array}$ & $2.1 \times 10^{5}$ & $\begin{array}{l}\text { Steel } \\
H-250 \\
\text { c.t.c=1.4 }\end{array}$ \\
\hline
\end{tabular}

Table 11 Timing of countermeasures implementation

\begin{tabular}{|c|l|}
\hline Timing & \multicolumn{1}{|c|}{ Timing of the countermeasures } \\
\hline 1 & Never protected \\
\hline 2 & 15 years after the start of service \\
\hline 3 & $\begin{array}{l}17 \text { years after the start of service } \\
\text { (Actual timing of Tagokura Tunnel) }\end{array}$ \\
\hline 4 & 19 years after the start of service \\
\hline
\end{tabular}

\subsection{Results of analysis}

\subsubsection{Convergence}

Figure 11 shows the progress of convergence obtained from the analysis, while Fig. 12 illustrates changes in the convergence speed averaged over two years before and two years after the implementation of countermeasures. These figures confirm that the implementation of the measures reduces the convergence speed. In this analysis, however, the ground strength decreased at an equivalent rate irrespective of whether countermeasures were applied. It should be noted, therefore, that the convergence speed gradually increased in any case, even when countermeasures were implemented. Nonetheless, the convergence speed can be reduced by increasing the number of element measures in the combination of damageproofing applications. Particularly in Case 4 where struts were used, the tunnel convergence speed remained low even 30 years after the start of service when cohesion had decreased to $1 / 10$ of the initial value. This means that the effect of the countermeasures remained unchanged even after 30 years.

Regarding the compression fracture, the edge strain inside the crown exceeded $3,500 \mu 16$ years after the start of service in unprotected cases, 17 years after with combination 2 , and 27 years after with combination 1 , suggesting a risk of compression failure. This is not the case, 


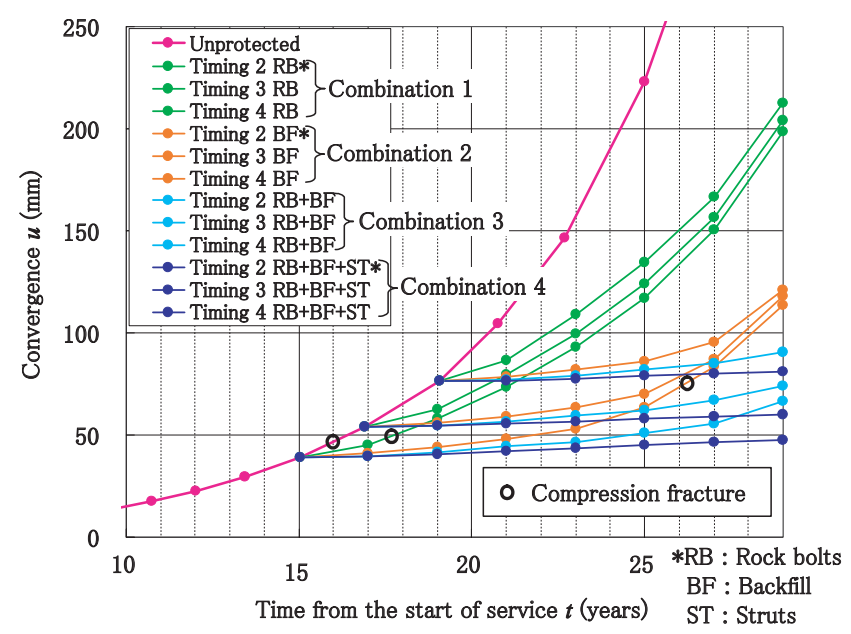

Fig. 11 Progress of convergence

however, with combinations 3 or 4 , thus proving the effectiveness of the countermeasures.

\subsubsection{Ground fracture}

The top row in Table 12 shows the failure zones of the ground in the case of counter measure implementation time 2 (implementation 15 years after the start of service). Figure 13 shows the failure zones at the SL in the horizontal and vertical directions (see the top row in Table 12 for a definition of the failure zone). As explained in paragraph a), the implementation of countermeasures suppresses the expansion of ground failure regardless, in the same way as the case of convergence. In combinations 1, 3 and 4 (in which backfill grouting was adopted), the effect of the countermeasures was particularly significant in suppressing the failure of the ground in both the horizontal and vertical directions.

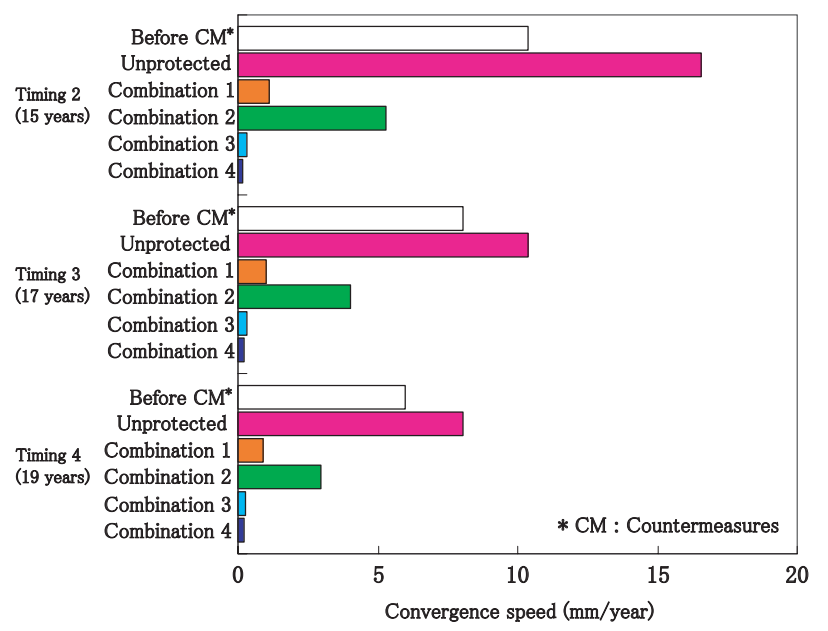

Fig. 12 Changes in the convergence speed (averaged over two years and over two years after the implementation of countermeasures)

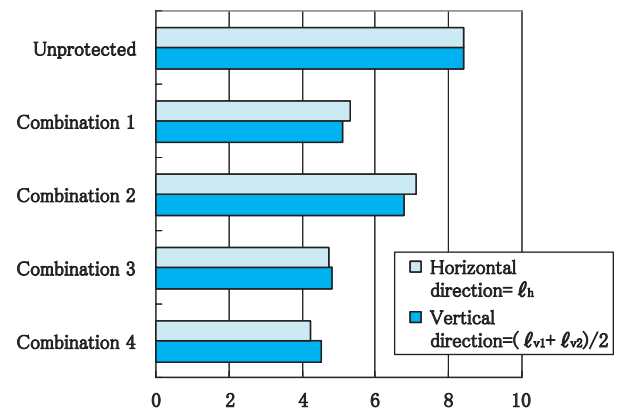

Fig. 13 Changes in the failure zone of the ground

\subsubsection{Lining fracture}

The bottom row in Table 12 shows the failure zone

Table 12 Changes in the failure zone from the implementation of countermeasures (application time 2, and 25 years after the start of service)

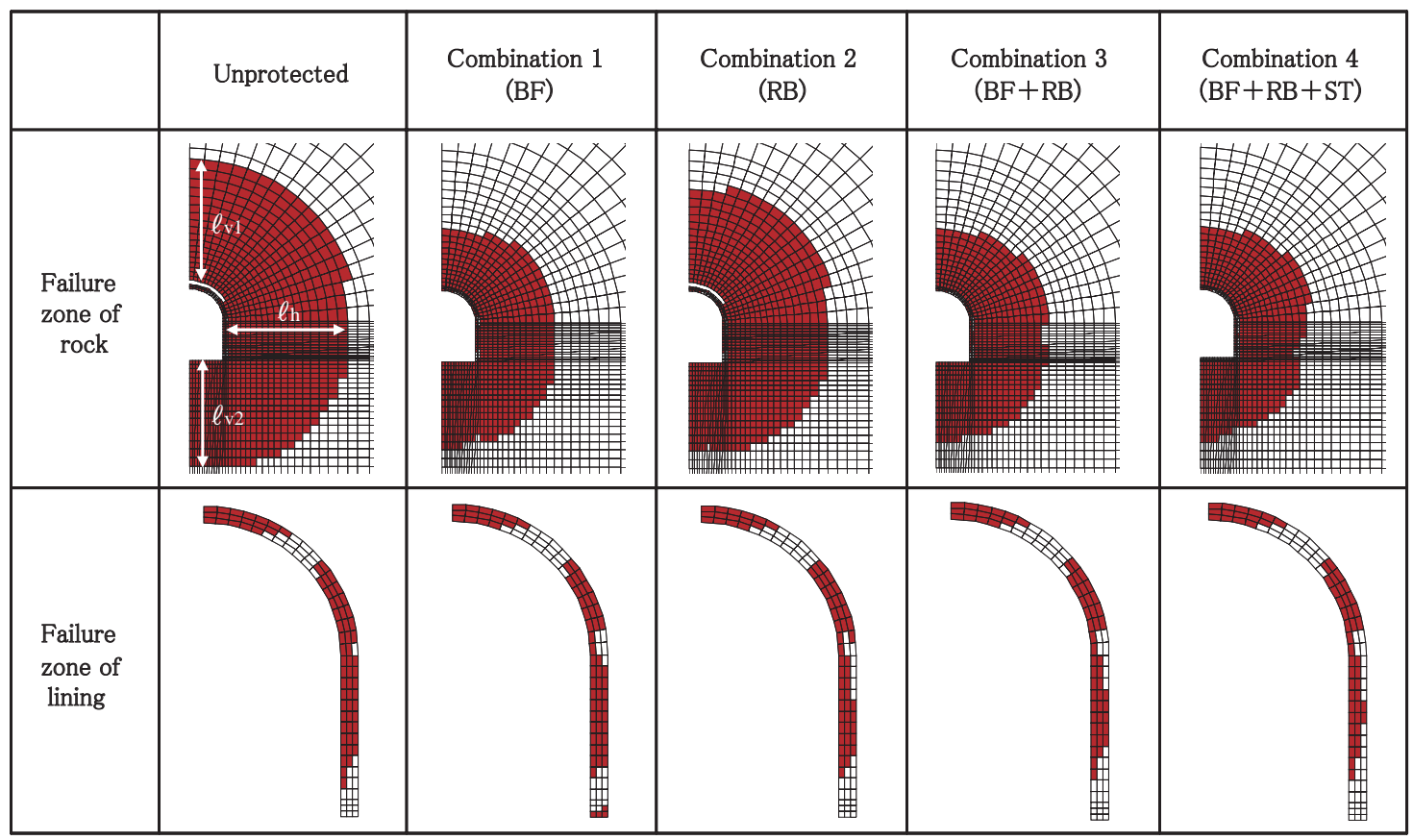


(where cracking occurred) in the lining. The areas of the lining arch section and sidewalls were divided into numerous element zones, and Fig. 14 compares the number/length of the failure element zones with the total number/length of element zones. With respect to lining fracture, a similar tendency to that of the ground is seen with the lining. With combinations 2 to 4 , in which rock bolts (RBs) were used, the countermeasures effectively suppressed the expansion of the failure zone, presumably because of the prestress effect of rock bolts sewing the lining to the ground and suppressing cracking. In combination 1 (backfill grouting), however, the countermeasures did not suppress the progress of cracking on the sidewalls as effectively as in paragraphs a) or b) (although they did suppress its progress to some extent at the arch section). Rather, they expedited cracking on the sidewalls. Note, however, that rock bolts do not suppress convergence itself to such a significant extent (as shown in Fig. 12).

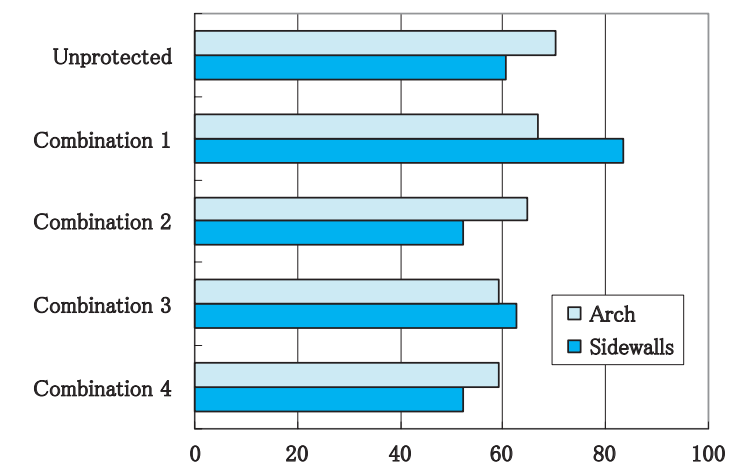

Fig. 14 Changes in the failure zone of the lining

\subsubsection{Application to discussion of the timing of implementation for countermeasures}

Here we discuss countermeasures and the timing of their implementation.

Together with the analytical results, an $80-\mathrm{mm}$ convergence line is cited in Fig. 11 as an example of the threshold convergence value to avoid infringement on the construction gauge. As discussion of the threshold values against the required performance remain at the research level, no method of setting these values has yet been established. If one of the design conditions is to prevent the occurrence of compression fracture at a point 30 years after the start of service, combination 3 (backfill grouting plus rock bolts) will be needed 15 years after the tunnel is put into use. It may also be possible to cope with compression fracture through flaking preventive work. If it is necessary to prevent infringement on the construction gauge at a point 30 years after the start of service, however, it will be necessary to implement combination 3 (backfill grouting and rock bolts) after 17 years or combination 4 (backfill grouting, rock bolts and struts) after 19 years (two years later than combination 3 ). Combination 4 will also be necessary as a fundamental measure if deformation should be suppressed completely in the future for important sections.

The above outcome clarifies that the timing of counter measure implementation can be discussed through analy- sis with these two variables (countermeasures and the timing of their implementation) as parameters using the technique adopted in this study, which also considers the concept of time.

\section{Conclusion}

In this research, while closely monitoring tunnel deformation caused by ground pressure, the authors analyzed tunnel deformation behavior using a ground deformation model, studied strength reduction curve configurations, investigated their relation to the progress of deformation, verified the validity of the analysis technique, and discussed the applicability of the technique in the real world. The effects of countermeasures, which had previously been evaluated based on the relationship between stress and convergence, can now be evaluated from the viewpoint of the relationship between time and convergence.

Having set threshold values for convergence to prevent compression fracture, it is now possible to discuss countermeasures and the timing of their implementation to satisfy these values.

The efficiency of management and maintenance of structures should be improved further, and the technique discussed in this paper may be applicable as a means of asset management that can be introduced in the future. The authors plan to improve the precision of analysis, repeat the application of the technique to actual cases, and continue in-depth research to establish a practical model for this purpose.

\section{Acknowledgement}

The authors wish to express their sincere gratitude to Mr. Yoshiteru Kawakami (JR Soken Engineering) and Mr. Yoshiyuki Shigeta (Dia Consultants), who kindly extended their cooperation to the authors in the implementation of this study.

\section{References}

[1] Matsunaga, T., Kumasaka, T. et al., "A Study on Prediction and Reinforcement of Tunnel Deformation Considering the Time Degradation of the Rock Mass Strength," Journals of the Japan Society of Civil Engineers, No. 799/III-72, pp. 75-88, 2005 (in Japanese).

[2] Nozawa, S., Ito, T. et al., "Kisetu Tonnel no Bouatsu wo Kokuhuku," Tunnels and Underground, 1992 (in Japanese).

[3] Aydan, O., Akagi, T. et al., "Prediction of Behavior of Tunnels in Squeezing Ground," Journals of the Japan Society of Civil Engineers, No. 448/III-19, pp. 73-82, 1992 (in Japanese).

[4] Jiang, Y., Ezaki, T. et al., "Quantitative Analysis of the Ground Characteristic Curve in Tunneling," Proceedings of the Japan Symposium on Rock Mechanics, 9, pp. 767-772, 1994 (in Japanese). 